Article

\title{
From Social Information to Social Norms: Evidence from Two Experiments on Donation Behaviour
}

\author{
Timo Goeschl ${ }^{1}$, Sara Elisa Kettner ${ }^{1,2}$, Johannes Lohse ${ }^{3, *}$ (i) and Christiane Schwieren ${ }^{1}$ \\ 1 Department of Economics, University of Heidelberg, Bergheimer Str. 20, 69115 Heidelberg, Germany; \\ goeschl@eco.uni-heidelberg.de (T.G.); kettner@conpolicy.de (S.E.K.); \\ christiane.schwieren@awi.uni-heidelberg.de (C.S.) \\ 2 ConPolicy-Institute for Consumer Policy, Friedrichstr. 224, 10969 Berlin, Germany \\ 3 Department of Economics, University of Birmingham, JG Smith Building, Birmingham B15 2SB, UK \\ * Correspondence: j.lohse@bham.ac.uk; Tel.: +44-(0)121-414-6221
}

Received: 22 August 2018; Accepted: 30 October 2018; Published: 4 November 2018

check for updates

\begin{abstract}
While preferences for conformity are commonly seen as an important driver of pro-social behaviour, only a small set of previous studies has explicitly tested the behavioural mechanisms underlying this proposition. In this paper, we report on two interconnected experimental studies that jointly provide a more thorough and robust understanding of a causal mechanism that links social information (i.e., information about the generosity of others) to donations via changing the perception of a descriptive social norm. In a modified dictator game, Experiment 1 re-investigates this mechanism adding further robustness to prior results by eliciting choices from a non-student sample and by implementing an additional treatment that controls for potential anchoring effects implied by the methods used in previous investigations. Experiment 2 adds further robustness by investigating the link between social information, (descriptive) norm perception and giving at the individual, rather than the group average, level. We find that an exogenous variation of social information influences beliefs about others' contributions (descriptive social norm) and, through this channel, actual giving. An exploratory analysis indicates that this causal relationship is differently pronounced among the two sexes. We rule out anchoring effects as a plausible confound in previous investigations. The key findings carry over to the individual level.
\end{abstract}

Keywords: Social Norms; Donations; Experiment; Social Information; Altruism

\section{Introduction}

The desire to adhere to social norms is thought to be a strong predictor of individuals' pro-social behaviour [1-6]. Individuals tend to be more cooperative in social dilemmas or give more to charitable causes when such behaviour is perceived to be the social norm. This holds for both types of social norms commonly distinguished in the literature, whether for descriptive norms, which refer to expectations that individuals hold regarding the most common behaviour in a situation, and for injunctive norms, which refer to expectations regarding what others think should be done in a given situation [7]. Experimental investigations provide controlled evidence to support these claims. One strand of experiments uses treatments in which subjects receive, prior to making their own decision, so-called descriptive social information, i.e., information about the pro-social behaviour of others. Shang and Croson [8] find that donations to a public radio station increase (decrease) when listeners observe high (low) donations made by another listener. Similarly, Frey and Meier [9] show that students are more likely to give to a student aid fund when they observe that a large share of their peers has donated in the past, and Alpizar et al. [10] report a significant increase in giving to a national park, when soliciting donations from visitors who are made aware of the significant contributions made by previous visitors. 
Another strand of experiments deploys designs that also provide information regarding injunctive norms. A key paper in this context is Bicchieri and Xiao [3], who directly compare the effect of descriptive and injunctive norms in the dictator game. The descriptive norm is implemented through social information on the most common behaviour among previous participants, the injunctive norm through social information on the behaviour that a majority of participants see as appropriate in this task. They find that subjects in the role of dictator are more likely to offer an equal split, if they are either informed that this has been the most common behaviour or the behaviour seen as most appropriate by dictators in a previous session. However, when participants receive social information on both norms and this information is not aligned, then sharing behaviour is more strongly affected by descriptive norms. ${ }^{1}$

While the link between providing social information and pro-social behaviour is well documented, less is known about the underlying behavioural mechanism. Theoretical explanations commonly invoke a preference for conformity [16] or self-image concerns [17,18]. These theories suggest that deviating from a norm results in disutility, while adhering to it leads to a utility gain even when transgressions or compliance are not publicly observable. Social information would activate this behavioural mechanism either by increasing norm salience (by reminding decision makers about the existence of a descriptive or injunctive norm) or by changing individuals' norm perception. So far, this behavioural mechanism remains little tested, and the evidence linking the provision of social information, its effect on the perception of an existing norm and the effect on pro-social behaviour is confined to a very small set of studies.

In this paper, we report on two interconnected experimental studies whose joint contribution is to provide, through careful design choices and through eliciting choices from a non-student population, a more thorough and robust understanding of this causal mechanism. Together, they contribute to the existing literature by establishing, in an incentivized setting, whether social information affects the perception of a descriptive social norm and thereby affects giving to a pro-social cause. By eliciting empirical expectations, we shed more light on a mechanism that operates through affecting descriptive norm perception. We implement additional design variations that provide further robustness to previous results [3]. Experiment 1 follows Croson et al. [19], who provide social information in a survey experiment on charitable giving and, through mediation analysis, establish that social information affects hypothetical giving behaviour through changing the perception of a descriptive norm. Our design overcomes the potential hypothetical bias implicit in survey designs by implementing an incentivized design in which participants can donate actual money. In this, it builds on Bicchieri and Xiao [3], who use a classic dictator game combined with providing information on descriptive and injunctive norms and eliciting corresponding expectations. Their paper is an important stepping stone that highlights how receiving social information can affect expectations about both a descriptive norm and an injunctive norm at the same time. It is thus difficult to disentangle the independent influence that both kinds of norms have on behaviour [1]. In their experiment, Bicchieri and Xiao [3] provide convincing evidence that both kinds of expectations can be affected to a similar degree by the same piece of information, but that the resulting pro-social behaviour is mainly affected by empirical expectations, with normative expectations having little independent effect. This insight is central for understanding the effect of social information on pro-social behaviour in situations where descriptive and injunctive norms are not aligned. Experiment 1 re-investigates this descriptive norm channel first identified in Bicchieri and Xiao [3] adding further robustness by using a non-student subject pool, by employing a modified dictator game with a real-world public good, by using a set of

1 The effects of social information on behaviour are not confined to the domain of generosity, with comparable relationships documented in many other areas such as energy conservation [11], political participation [12], honesty [13], retirement saving [14] and high stakes career choices [15]. 
social information treatments with a different range of descriptive norms ${ }^{2}$ and by an extra treatment that controls for possible anchoring effects in the social information treatments. Experiment 2 provides additional robustness by proposing a new 'revised choice' design for investigating the link between social information, (descriptive) norm perception and giving at the individual level rather than at the group average level.

Both of our experiments utilize a modified dictator game [20] in which subjects can contribute to an existing public good through their giving. This task format and the specific public good we employ (climate change mitigation) have the advantage of conceivably limiting the role of reciprocity as an alternative mechanism through which social information could affect behaviour in our setting. ${ }^{3}$ As is common in the literature, we compare donations in a baseline condition to a setting in which subjects receive social information in the form of either low or high average contributions observed for subsets of the baseline population prior to making their own decision. Our approach differs from previous field studies in also eliciting participants' beliefs regarding the pro-social behaviour of others through an additional and incentivized task. This allows us to study the effect of social information on norm perception. In the first experiment, we do so in the controlled environment of an artefactual field experiment to which we invite members of the general public [24]. The second experiment is a lab experiment run with student subjects. Providing social information should have the strongest effect on norm perception in situations where there is some ambiguity about the ruling norm. This is likely to be true in our setting in light of the high variance of donations in the baseline.

We use two different empirical strategies to investigate the proposed mechanism. As in Croson et al. [19], we conduct a mediation analysis. This analysis is supplemented by a regression approach that uses random treatment assignment as an instrument by design for norm perception $[3,25,26]$. In an additional treatment, we rule out that instead of affecting norm perception, the effect of social information mainly operates through a known psychological confound, namely anchoring [27]. Since it has been shown that irrelevant numerical information (e.g., a birth date) can affect giving, the same could be true for any given number including those used to convey information on others' giving behaviour in the high and low treatment. To validate our results against this concern, we introduce an irrelevant information treatment in which subjects are shown a number that conveys no information on a contribution norm.

The second experiment resembles the first in most of its central elements, but is designed to better understand the role of social information at the individual level. For this purpose, after submitting an initial decision, subjects receive new information on the donation behaviour of others. They are then given the opportunity to either confirm or revise the amount they wish to donate. In this, our design resembles the sequential dictator game proposed in Cason and Mui [27]. Eliciting choices in this order provides us with an opportunity to study how subjects react to a discrepancy between their initial donation, their expectation of others' behaviour (their initially perceived descriptive social norm) and the actual observed behaviour of others.

The results of the two experiments and their significance can be summarized as follows: both experiments confirm and offer additional support for the existence of a positive and causal

2 Bicchieri and Xiao [3] compared a selfish norm to a norm that suggests an equal split. We compare a norm suggesting a low donation amount and a norm suggesting a high donation amount to a situation where no social information is provided.

3 There are other common experimental task formats in which reciprocity is a more plausible explanation as to why subjects react to social information. For instance, in standard repeated public good experiments, a significant fraction of subjects is known to react to social information; they increase their contributions upon observing high contributions made by other group members and decrease their contributions upon observing low contributions (see, e.g., Keser and Van Winden [21], Fischbacher et al. [22] or Chaudhuri [23]). This form of conditional cooperation could be interpreted as either expressing preferences for conformity or as direct reciprocity (i.e., reciprocating the observed kindness of others). In a standard public goods game, subjects benefit immediately and directly from the contributions made by other group members. Thus, there is a large scope for reciprocity to materialize. In our experimental task, in contrast, the marginal benefit of a donation to another subject is close to zero and, due to the slow reactivity of the climate system, only materializes with significant delay. This greatly limits the room for direct reciprocity compared to the standard public goods game setting. 
link between social information and pro-social behaviour. Experiment 1 provides further evidence for a mechanism that operates through norm perception. Specifically, an exogenous variation of social information influences beliefs on others' contributions (descriptive social norm) and, through this channel, actual giving. Exploratory analysis indicates that this causal relationship between social information, beliefs and contributions might be differently pronounced among the two sexes. We complement the existing literature on social information by ruling out anchoring effects as a plausible confound implied by the methods used in previous investigations. Experiment 2 demonstrates that these results carry over to the individual level in the following way: when subjects experience a discrepancy between their own behaviour and the actual pro-social behaviour of others, they are more likely to revise their initial decision. Subjects are, however, not more likely to revise their initial decision, if they observe a discrepancy between their own empirical expectations and the actual giving of other subjects.

The remainder of this paper is organized as follows: in Section 2, we describe the design of both experiments, followed by behavioural hypotheses derived from the existing literature in Section 3 . Section 4 contains the results. We conclude with a brief discussion in Section 5 .

\section{Experimental Procedures and Design}

\subsection{Decision Task and Treatments: Experiment 1}

On the first screen, we remind subjects that they will receive $€ 10$ as compensation for taking part in the study-as previously announced in the recruitment materials. In a modified dictator game [20], they are then given the opportunity to donate any share of their compensation to a common account and are told that this account would be used by the experimenters to offset global $\mathrm{CO}_{2}$ emissions. ${ }^{4}$ A decision to give up some of the compensation therefore provides a global public good whose beneficiaries are distributed across the globe and, as the instructions emphasize, will experience the potential benefits of reduced $\mathrm{CO}_{2}$ with significant temporal delay. Subjects' personal monetary benefit from the donations made by other subjects in the experiment is therefore close to zero and at most marginal. This is a desirable feature of this design: in contrast to standard public good experiments (see, e.g., Keser and Van Winden [21], Fischbacher et al. [22] or Chaudhuri [23]), this design provides little traction for reciprocity or 'being the sucker' as motives for subjects' response to the information that others have donated a high or low amount.

The two social information treatments were equivalent to the BASEline in all stages except one: before stating their preferred donation amount, subjects reached an additional screen that informed them about the average donations made by previous participants. In the HIGH social information treatment, subjects were informed that the experiment had been conducted before and that fifty previous participants had donated $€ 7$ on average. Similarly, in the LOW social information treatment, subjects learn that fifty prior participants had donated $€ 1$ on average. We choose $€ 1$ and $€ 7$ to be below and above median donations in the BASEline. This allows us to study how norm perception and behaviour of the median subject is affected by a novel piece of information. The exact text shown on the (HIGH or LOW) information screen read as follows:

“In previous sessions of this experiment, 50 participants on average gave $€ 7$ (HIGH) / $€ 1$ (LOW) to retire $\mathrm{CO}_{2}$-permits"

4 As in Diederich and Goeschl [28] and Löschel et al. [29], their decision was implemented by retiring $\mathrm{CO}_{2}$-permits via the EU Emissions Trading System. Before subjects made any decision, they were given some basic information on the exact procedures via a brief text that informed them about greenhouse gas emissions, the functioning of the offset scheme and the amount of $\mathrm{CO}_{2}$ that could be reduced by $€ 1$. We also explained to participants that a certificate of total emission reductions issued by the emission-trading-agency would be posted at a public notice board of the university where the study was conducted at the end of the study period, to allow them to verify the total (but not the individual) amount of money donated to carbon reductions. 
These procedures slightly deviate from the social information treatments in previous studies with the aim of enhancing the perception of a commonly shared (descriptive) norm. Instead of referring to only one previous donor in a minimal design [8], we refer to donations made by a larger group of individuals. Similarly—having all decided to take part in the same experiment—our reference group could arguably be perceived as more similar than in previous experiments [10], which again could enhance the perception of a commonly shared norm [30]. To avoid deception, we make sure that both statements used in the social information treatments are factually correct. They are derived from the respective behaviour of 50 subjects making their decisions in BASE sessions conducted several months before the social information treatments. As in previous studies $[3,8]$, the information we provide is based on a selected subset of previous participants, and the formulation we choose does not suggest in any conceivable way that it represents a representative subset. ${ }^{5}$

We conduct one additional control treatment (NUMBER) to account for the possibility that cognitive anchoring effects-based on the number shown on the information screen itself rather than the social information contained in it-could influence giving. Previous studies have found that presenting an unrelated number (e.g., a date of birth or a social security number) can affect subsequent donation decisions because the number serves as a mental anchor [27]. We thus conduct a control treatment that allows us to investigate the importance of this potential confound in our setting. In NUMBER, the information screen contains the same number (seven) as the HIGH treatment. This number, however, is embedded in a context that does not provide any reference to a possible social norm. In particular, we inform participants that 50 prior participants from the same experiment were living within a seven-kilometre radius. ${ }^{6}$

A central difference to previous field experiments is that our design includes an additional task that can be used to explicitly test for the underlying mechanisms through which social information affects behaviour. To reach a better understanding of this mechanism, we analyse how the perception of a (descriptive) social norm is affected by social information. For this purpose, we ask participants to state their beliefs regarding the donation behaviour of other participants. A descriptive social norm is defined as the behaviour that is seen as most common in a given situation [1,33]. We thus asked participants about their beliefs regarding the mean donation made by the other participants in their experimental session. There was an incentive in place for stating a correct belief: if stated beliefs were within the range of $-€ 0.5$ and $+€ 0.5$ around the true session mean, participants received an additional payment of $€ 2$. An absolute deviation of $€ 1.5$ from the true average yielded $€ 1{ }^{7}$

\subsection{Decision Task and Treatments: Experiment 2}

In Experiment 2, we extend the social information treatments of Experiment 1 (HIGH and LOW), with the aim of studying in more detail how social information affects pro-social behaviour at the individual level. In particular, we are interested in the degree to which the strength of a deviation between the perceived norm or own behaviour and observed behaviour (i.e., social information) affects the propensity to change donation behaviour in a subsequent decision. For this purpose, subjects go through the same donation and belief elicitation tasks as in the BASE treatment of Experiment 1. After stating their beliefs, participants reach an information screen similar to those in the HIGH

5 This obviously does not rule out the possibility that some subjects might still misunderstand the factually correct information we provide in that way, just as some subjects in Bicchieri and Xiao [3] might wrongly believe that the session data they are shown come from a representative session. Our method, thus, clearly avoids actively misleading subjects in any way; a clear form of deception. We leave it to our readers to decide whether the scope for such misunderstanding is sufficiently small to still conform to the commonly shared norm of avoiding deception in experimental economics or rather falls into a grey area. We refer the interested reader to Ortmann and Hertwig [31] and Colson et al. [32] for a more general discussion of deception and the different views that exist within the discipline as to what such grey area might encompass.

6 As in the other treatments, this information is based on the actual place of residence of baseline participants.

7 In a few, early baseline sessions, belief elicitation was not incentivized. To increase the reliability of estimates we added an incentive mechanism in later baseline sessions, as well as all social information sessions. 
and LOW treatments. There are two key differences to Experiment 1, apart from reversing the order. The first is that the social information provided stems from only two randomly drawn participants in their session. Thus, the information provided has, on the one hand, a higher variance. On the other hand, as the information emerges only from two other individuals, its effects on changing norm perception might be weaker. The second key difference lies in the introduction of a 'revised choice' design: subjects reach a second donation screen after receiving social information. On this second screen, subjects are asked to either confirm or revise their initial decision on the amount to be donated. Thus, in contrast to Experiment 1, we are not interested in the direct effect of social information on beliefs, which are elicited before subjects receive the additional information. Rather, eliciting choices and beliefs in this order allows us to study, for each participant, how differences between their initial donation or perceived norm and observed behaviour (social information) affect a change in behaviour between initial and final choices.

\subsection{Procedures}

Data were collected between November 2011 and July 2012 (Experiment 1) and in July 2014 (Experiment 2) at an Experimental Lab of a large German university, and both experiments were implemented in z-Tree [34]. ${ }^{8}$ Overall, we conducted 26 sessions with up to 15 subjects per session (Experiment 1: 23 Sessions, Experiment 2: 3 Sessions). Upon arrival, subjects were seated at a random computer terminal, and a printed version of the general instructions was handed out and read aloud by one of the experimenters. Any form of communication between participants was not allowed, and questions were answered in private. Subjects could not participate in more than one session and submitted their decisions anonymously. For this purpose, they generated a personal code that was also used for anonymous payment. At the end of each session, subjects received a sealed envelope with an earnings receipt based on this code. The payment itself was executed in a different room by a research assistant who was not present at any time of the experimental sessions. Thus, overall earnings were not observed by the experimenters, and subjects were made aware that their identity would not be revealed to them. At the end of a session, subjects completed several follow-up questionnaires eliciting standard demographics, as well as questions regarding the experimental tasks and the public good offered in the donation task (climate change mitigation). Sessions lasted around 75 min (Experiment 1) and $45 \mathrm{~min}$ (Experiment 2), and the average payment for all tasks in Experiment 1 was $€ 15.47$ ranging from $€ 1.05-€ 26.00 .^{9}$ The average earnings for Experiment 2 was $€ 11.20$ (Min.: $€ 4$ and Max.: $€ 14$ ) including a show-up fee of $€ 4$.

To achieve some parallelism with previous field experiments, while at the same time maintaining the possibility to elicit additional information required to identify the underlying behavioural mechanisms, we conducted an artefactual field experiment [24]. For this purpose, we recruited $\mathrm{N}=274$ participants from the general public to Experiment 1 . The BASEline contains 144 observations, the HIGH and LOW social information treatments 47 subjects each and the irrelevant information treatment (NUMBER) 36 subjects. Participants from the general population were recruited via advertisements in two different local newspapers with a combined readership of approximately 160,000 readers. As an additional recruitment tool, leaflets about the experiment were posted in all neighbourhoods and public places of the city in which the study was located. The response rate to all recruitment tools was similar, and there were no significant differences in demographic attributes and decisions within the experiment. Individuals interested in participating contacted a research assistant for further information and were invited to a session, randomizing treatments at the session level. The research assistant made sure that none of the subjects had previous experience with

8 The procedure, as well as a translation of the $\mathrm{z}$-Tree instructions are provided in the Appendix.

9 Total earnings and duration for Experiment 1 encompass a second task (public goods game) that we analyse in a separate paper [35] and that took place subsequent to any decisions analysed in this paper. 
economic experiments or had taken part in a previous session. The BASE sessions were conducted before the other treatments in order to be able to derive the social information provided in the subsequent information treatments (HIGH, LOW, NUMBER) from actual behaviour. As expected, random assignment led to nearly balanced demographic attributes across treatment cells. There were no significant differences for the attributes displayed in Table A1 of the Appendix, with the exception of income. ${ }^{10}$ Experiment 2 was a follow-up study conducted with an $\mathrm{N}=45$ sample of student subjects recruited from the standard subject pool via the Online Recruitment System for Economic Experiments (ORSEE) [36]. We excluded participants with prior experience in social-preference tasks.

\section{Hypotheses}

In the subsequent section, we formulate hypotheses based on observations from prior studies and the mechanism of conformity suggested therein.

\subsection{The Effect of Social Information on Behaviour}

Providing social information could affect pro-social behaviour in opposite directions: crowding-in or crowding-out of giving [8]. Theory predicts that individuals who only care about the aggregate level of the public good provided via their donations reduce their giving by the same amount by which they learn that donations made by others exceed their expectations. Such complete crowding-out was originally suggested by Roberts [37]. Models of impure altruism, in which individuals derive some warm glow utility from their own donation, also suggest crowding-out, but less than complete [38]. In contrast, according to the crowding-in hypothesis, individuals are expected to contribute larger amounts when they observe others contributing as well. Such crowding-in effects have been attributed to a preference for conformity such that individuals prefer to match the giving behaviour of their peers [16,39]. Previous experiments on the effects of providing social information suggest that crowding-in could dominate crowding-out $[8,10]$. This implies that social information suggesting a high donation to be the norm will lead to higher giving than social information that suggests low donations to be the norm. Since we use a similar experimental design, we expect crowding-in effects to dominate, leading to the following hypotheses:

Hypothesis 1a. Subjects in the HIGH treatments will donate larger amounts than subjects in the BASE treatment where no social information is provided.

Since Croson and Shang [40] found a reduction in donations when social information suggests selfish behaviour to be the descriptive norm, we expect a similar outcome for the LOW treatment:

Hypothesis $\mathbf{1 b}$. Subjects in the LOW treatments will donate smaller amounts than subjects in the BASE treatment where no social information is provided.

\subsection{Mechanisms by Which Social Information Affects Behaviour}

It has been suggested that social information may affect pro-social behaviour through its effect on the perception of a descriptive social norm. While most previous papers have only tested for this exact mechanism implicitly, they usually assumed to some degree that social information affects pro-social behaviour through a preference for conformity [16,39]. Individuals holding such preferences receive additional utility from adhering to a (perceived) social norm while experiencing disutility from breaking a norm. Preferences for conformity are actionable even in the absence of audience

10 Our core results continue to hold when controlling for the demographic attributes contained in Table A2. As self-reported income might not capture the wealth status of an individual, we further report participants' assets as a binary variable indicating whether participants own a house or an apartment. With respect to reported assets, there exists no significant difference between the four treatments. 
effects, as individuals simply follow their internal moral calculus. A mechanism of social information reflecting such preferences can be summarized as working through the following two steps. First, it assumes that subjects use the social information they observe to update their empirical expectations regarding others' typical contribution behaviour (descriptive norm). Second, they then adapt their own generosity to conform with this updated norm [19]. Bicchieri and Xiao [3] describe a similar mechanism and find support for it in their data. We follow these two steps when formulating our hypotheses:

Hypothesis 2a. Social information affects the perception of a descriptive social norm, leading to differences in stated beliefs in the HIGH, LOW and BASE treatment in line with the information provided.

Hypothesis $\mathbf{2 b}$. Differences in donations between treatments are driven by the effect of social information on beliefs.

In an additional control treatment (NUMBER), we investigate a potential confounding effect. In particular, there could be the concern that anchoring effects are present in the social information treatments. If so, they would lead to wrongly attributing any effects on behaviour to the social information provided instead of also reflecting the fact that simply presenting a number without any normative context could already influence pro-social behaviour. It has been shown that anchoring effects make individuals recall a figure from their short-term memory when they are uncertain about aspects of the decision environment [41]. Importantly, anchoring effects of this kind have been shown to influence pro-social behaviour: Cason and Mui [27] report a relationship between dictator transfers and irrelevant information, i.e., the date of birth. An alternative hypothesis reflecting this concern reads as follows:

Hypothesis 3. If individuals are presented with irrelevant information-providing a NUMBER from the contribution space without any reference to a norm - they contribute larger amounts compared to a setting without any additional information (BASE). If anchoring fully accounts for any effects in the social information treatments, there are no differences between HIGH and NUMBER.

Experiment 2 was designed to test the underlying mechanism at the individual level. If a preference for conformity is driving social information effects, individuals should be more likely to revise their initial donation amount when the differences between their own behaviour or perceived norm and observed behaviour of others is large. In particular, we expect:

Hypothesis 4a. Subjects receiving social information that suggests a high donation norm to donate higher amounts.

Hypothesis $\mathbf{4 b}$. The likelihood of a revision depends on the strength of the social information received.

\section{Results}

In the following, we present tests for these four hypotheses. For Hypotheses 1-3, we rely on data from Experiment 1, while Hypotheses 4 is tested with data from Experiment 2.

\subsection{Social Information Matters}

The effect of providing social information on the amount donated can be summarized as follows: in BASE, subjects give 31 percent of their initial endowment (median 20 percent), and 61 percent of subjects contribute a non-zero amount. ${ }^{11}$ This compares to an average donation of 44 percent of

11 Overall, these baseline results fall into a range comparable to that observed in Diederich and Goeschl [42] and Löschel et al. [29], who looked at contributions to the same public good. As these studies vary the price of giving, there is 
the initial endowment in HIGH and 27 percent in LOW. Differences in median giving are even more pronounced (HIGH: 50 percent, LOW: 10 percent), while the propensity to give is not as strongly affected by providing social information (HIGH: 70 percent, LOW: 60 percent). Figure 1 summarizes these outcomes and displays the results of the associated significance tests.
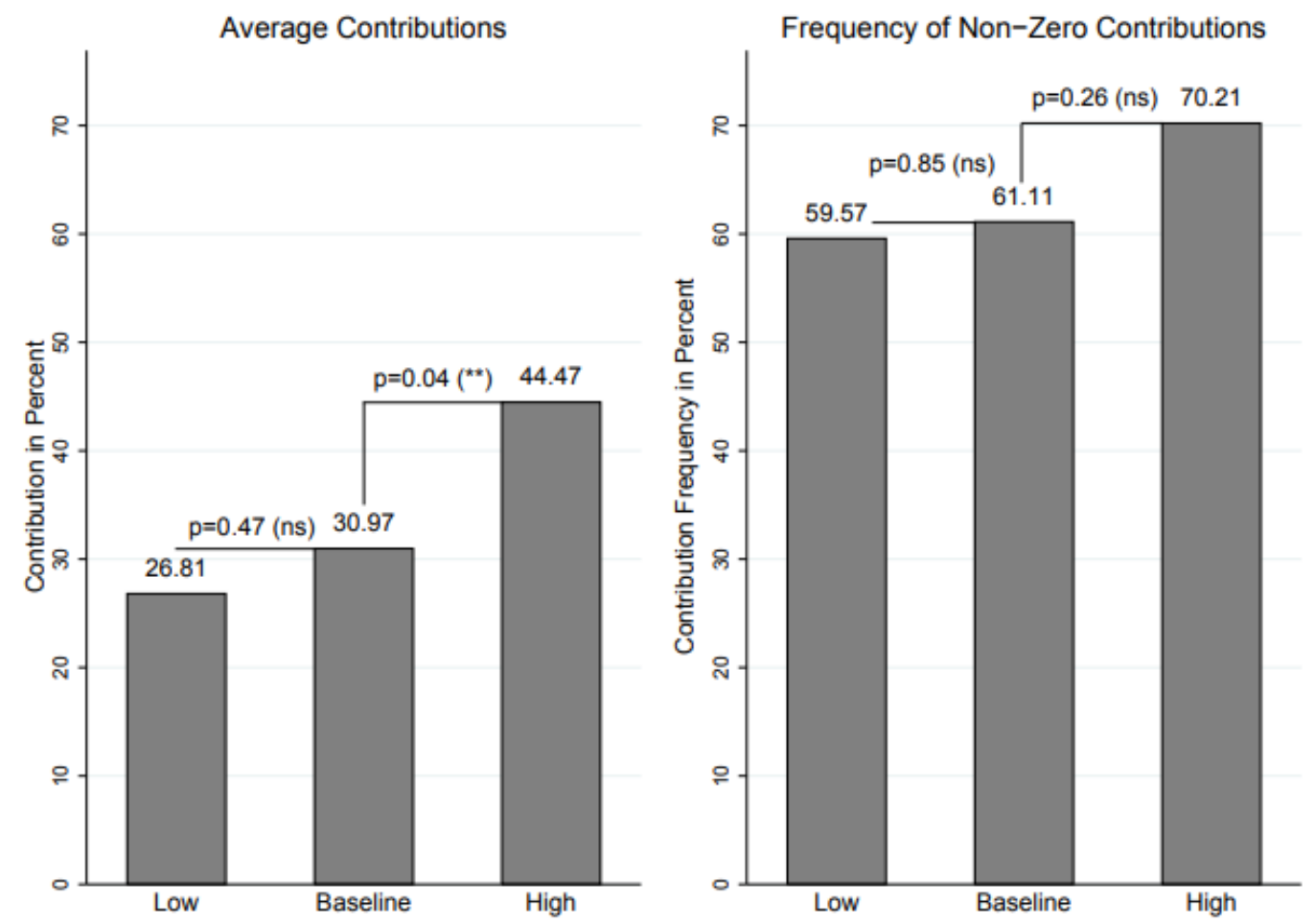

Figure 1. Average contributions and frequency of non-zero contributions by treatment.

In accordance with Hypothesis 1a, we find that providing HIGH social information significantly increases average donations by 43 percent relative to donations in BASE (Mann-Whitney test, $p=0.04$ ). The propensity to give is also slightly higher in HIGH compared to BASE, although not significantly so (Fisher's exact test, $p=0.26$ ). With respect to Hypothesis $1 \mathrm{~b}$, we do not find evidence that providing LOW social information reduces giving significantly. Average donations are slightly reduced, but neither the propensity to give nor the size of donations differ statistically compared to BASE (Mann-Whitney test, $p=0.47$; Fisher's exact test, $p=0.85$ ). ${ }^{12}$ These findings are robust to controlling for demographic attributes in a set of regressions presented in Table A2 of the Appendix. We summarize the above findings as:

Result 1a. Compared to BASE, donations (but not the propensity to give) are significantly higher when providing HIGH social information.

Result 1b. Compared to BASE, neither donations, nor the propensity to give are lower when providing $L O W$ social information.

only limited comparability to our setting. Carpenter et al. [43] used a similar elicitation method, but allowed participants to give to a charity of their own choosing. In their setting, donations reach 68 percent of the initial endowment.

12 One reason for a weaker effect of the LOW social information treatment, which is in line with the results we discuss in more detail below, could be that the information provided differs less from the expectations that subjects hold regarding the giving of others in BASE. 


\subsection{Mechanism}

\subsubsection{Changing Norm Perception}

It has been suggested that providing social information affects the perception of descriptive social norms and thereby actual behaviour. Here, we ask whether this proposed mechanism finds support in the data generated by Experiment 1. Our test is comprised of several steps that address the different parts of this statement.

In a first step, we simply compare subjects' stated empirical expectations between the two social information conditions (HIGH, LOW) and the BASEline where beliefs are elicited without providing social information beforehand. In accordance with the proposed mechanism, social information significantly affects beliefs about the contribution behaviour of others (i.e., the perceived descriptive norm). As shown in Figure 2, in BASE, stated beliefs amount to 38 percent of the endowment on average. Subjects alter their norm perception in line with the information they receive: in the LOW treatment, they expect giving to amount to 24 percent of the endowment, and in the HIGH treatment, they expect average giving to amount to 51 percent. Stated beliefs differ significantly at the 1\%-level (Mann-Whitney test). While subjects update perceived norms in the expected direction, updating is only partial, such that stated beliefs are not fully aligned with the social information provided. We summarize these observations as:

Result 2a. Providing social information has an effect on the perception of descriptive norms. Compared to BASE, subjects expect more giving by their peers in HIGH and less giving in LOW.

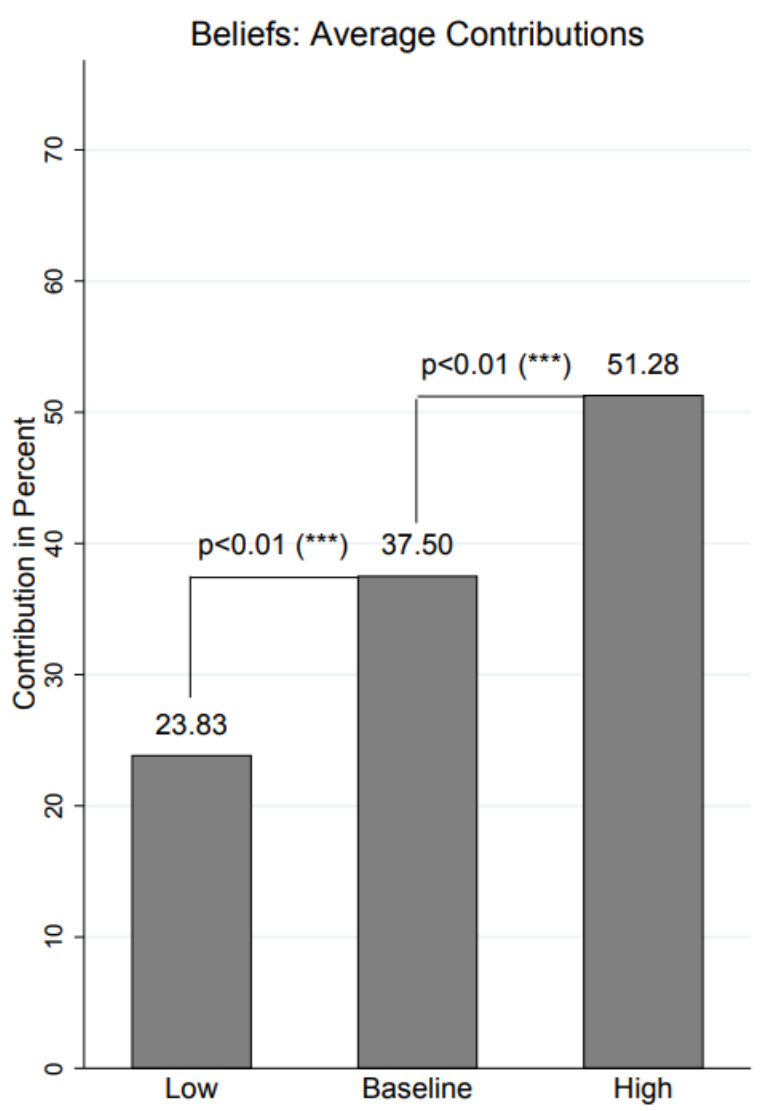

Figure 2. Beliefs about average contributions by treatment. 
Further evidence on the proposed mechanism comes from investigating the pairwise correlation between contributions and stated beliefs in each treatment. If a sufficient number of individuals hold preferences for conformity, there should be a positive correlation between the perceived norm and actual behaviour. This is true for each of the treatments with correlation coefficient $\rho$ ranging from 0.44 $(p<0.01)$ in BASE and $0.43(p<0.01)$ in LOW to $0.58(p<0.01)$ in HIGH.

A more sophisticated analysis is based on the results of two different regression frameworks summarized in Table 1. Specifications 1 and 2 form the basis of a simple mediation analysis [44]. In Specification 1, we regress the two dummies for the HIGH and LOW treatment on giving (as a percentage of the initial endowment). Restating Results $1 \mathrm{a}$ and $1 \mathrm{~b}$, there is a positive and significant effect of providing HIGH social information and a negative and insignificant effect of providing LOW social information. By including stated beliefs into the same regression framework in Specification 2 , we provide evidence for a mediating effect of norm perception on this relationship. With beliefs included, both treatment dummies become insignificant, while the regression coefficient for beliefs is positive and highly significant. This provides a first indication for the presence of a mediating effect. We investigate this effect more formally via a Sobel-Goldman test based on Specifications 1, 2 and (3). ${ }^{13}$ This tests finds that the reduction in treatment effects is significant for both the HIGH and the LOW treatment condition $(p<0.01)$. The sign of the coefficient for the LOW treatment even reverses. From this analysis, we conclude that descriptive social norms fully mediate the influence of social information on giving.

Table 1. Regression results: relationship of treatments, beliefs and contributions.

\begin{tabular}{|c|c|c|c|c|}
\hline & (1) & (2) & $\begin{array}{c}(3) \\
\text { 1st Stage }\end{array}$ & $\begin{array}{c}(4) \\
\text { 2nd Stage }\end{array}$ \\
\hline Dependent Variable & Contributions & Contributions & Beliefs & Contributions \\
\hline $\operatorname{High}(0=\mathrm{No}, 1=$ Yes $)$ & $\begin{array}{c}13.50 \text { ** } \\
(6.093)\end{array}$ & $\begin{array}{c}2.736 \\
(5.824)\end{array}$ & $\begin{array}{c}13.78^{* * *} \\
(3.104)\end{array}$ & \\
\hline Low $(0=$ No, $1=$ Yes $)$ & $\begin{array}{l}-4.164 \\
(5.865)\end{array}$ & $\begin{array}{c}6.514 \\
(5.891)\end{array}$ & $\begin{array}{c}-13.67^{* * * *} \\
(3.439)\end{array}$ & \\
\hline Beliefs & & $\begin{array}{c}0.781 * * * \\
(0.129)\end{array}$ & & $\begin{array}{c}0.644^{* * *} \\
(0.244)\end{array}$ \\
\hline Constant & $\begin{array}{c}30.97 * * * \\
(2.889) \\
\end{array}$ & $\begin{array}{c}1.682 \\
(4.417) \\
\end{array}$ & $\begin{array}{c}37.50 * * * \\
(1.643)\end{array}$ & $\begin{array}{c}8.644 \\
(9.452) \\
\end{array}$ \\
\hline$N$ & 238 & 238 & 238 & 238 \\
\hline$R^{2}$ & 0.029 & 0.213 & 0.164 & 0.203 \\
\hline Prob $>$ F / $\chi^{2}$ & $<0.01$ & $<0.01$ & $<0.01$ & \\
\hline
\end{tabular}

Note: contributions, as well as beliefs are reported in percentage of endowment; robust standard errors in parentheses; ${ }^{* *} p<0.05, * * * 0<0.01$.

In a final step, we test if this conclusion is robust against the concern that the mediator variable itself could be endogenous. In particular, if stated beliefs are themselves determined by prior choices, they might be endogenous in the prior analysis. To account for this potential problem, we follow previous studies on the role of potentially endogenous beliefs in economic games and rely on an instrumental variable framework (IV) $[25,26,46]$. As subjects are randomly allocated to the different social information treatments, by design, treatment assignment can serve as an exogenous instrument for beliefs. Under the validity of the exclusion restriction, this framework identifies the causal effect of beliefs on behaviour (ibidem). Specification 3 shows the first stage of a Two-Stage Least Squares (2SLS) estimation. Beliefs are significantly affected by the exogenous variation of social information

13 The Sobel-Goldman test is a test for the statistical significance of a mediation effect. It goes back to Sobel [45] and tests if the relationship between the independent variable and the dependent variable is affected in a significant way by the inclusion of the mediating variable. 
provision. ${ }^{14}$ Specification 4 displays the second stage regression in which contributions are regressed on instrumented beliefs. While the coefficient of beliefs is slightly smaller than in Specification 2 , it remains highly significant, indicating a causal relationship between norm perception and the amount given. ${ }^{15}$

Jointly, these results suggest that social information affects pro-social behaviour by changing norm perception. This is in line with a mechanism based on preferences for conformity. We summarize this as:

Result $\mathbf{2} \mathbf{b}$. There is evidence for a causal link between social information affecting norm perception and thereby amounts donated.

Does this mechanism apply uniformly within the sample or does it vary with observable characteristics? There is some suggestive evidence indicating that members of the two sexes might react differently to social information. Croson and Gneezy [47] reported females, in general, to be more sensitive to context variations or cues in experimental settings investigating social preferences. Providing social information could be seen as such a contextual variation. However, maybe more applicable to the specific context we are interested in here, Croson et al. [48] found males to react more strongly towards social information, albeit in a hypothetical choice experiment. Given this mixed evidence, we extend the previous analysis to explore whether females and males reveal systematic differences in contribution behaviour under the different social information treatments. In a second step, we repeat the IV approach to investigate whether the proposed mechanism applies uniformly across the two sexes.

Specification 1 in Table 2 reports regression results including dummies for treatments and gender, as well as their interaction. Specification 2 repeats the same analysis with additional controls for other demographic attributes included. The significant interaction effects found in both specifications suggest that female participants are more strongly influenced by providing HIGH, but not LOW, social information. The treatment effect for male participants is neither significant for the LOW, nor for the HIGH treatment. ${ }^{16}$

Based on the previously investigated mechanism, this gender-specific treatment effect might exist for two different reasons. First, social information might affect norm perception differently by gender. Second, males and females might adhere to social norms differently, even when the perception of the prevailing norm does not differ. We include interaction terms in the IV framework we introduce above to test whether one or both of these explanations can account for gender differences in the treatment effect. The first stage evidence shown in Specification 3 indicates no heterogeneity in the effect of social information on norm perception. ${ }^{17}$ Evidence from the second stage regression suggests that the desire to adhere to social norms is more pronounced among females. Beliefs are only weakly related to behaviour for males, while this relationship is stronger for females. Jointly, this analysis suggests that male participants are as likely as female participants to adapt their norm perception in line with the social information presented; however, they are less prone to adhere to this newly-perceived norm.

14 This mirrors the results of the non-parametric analysis. Furthermore, a large F-statistic $(F(2235)=23.73)$ indicates that instruments generated by random treatment assignment are not weak.

15 Testing for endogeneity formally via conducting a Hausman test indicates also that an endogeneity problem is not likely $(p=0.65)$

16 Non-parametric tests similarly show that giving in HIGH vs. BASE differs significantly for females (Mann-Whitney test, $p<0.01$ ), but not for males (Mann-Whitney test, $p=0.71$ ).

17 Comparing treatment effect between sexes individually reveals at most a weak difference (male-high vs. female-high, $F(1231)=0.01, p=0.93$; male-low vs. female-low, $F(1231)=3.26, p=0.07)$. Similarly, testing treatment differences in average beliefs separately for females and males results in significant effects when comparing high/low social information to the baseline. Hence, both males and females adapt their beliefs under social information to a similar extent. 
Table 2. Regression results: treatment effects, gender and the causal mechanism.

\begin{tabular}{|c|c|c|c|c|}
\hline & (1) & (2) & $\begin{array}{c}\text { (3) } \\
\text { 1st Stage }\end{array}$ & $\begin{array}{c}(4) \\
\text { 2nd Stage }\end{array}$ \\
\hline Dependent Variable & Contributions & Contributions & Beliefs & Contributions \\
\hline High $(0=$ No, $1=$ Yes $)$ & $\begin{array}{c}2.408 \\
(7.853)\end{array}$ & $\begin{array}{l}-0.299 \\
(8.170)\end{array}$ & $\begin{array}{l}8.921 * \\
(4.639)\end{array}$ & \\
\hline Low $(0=$ No, $1=$ Yes $)$ & $\begin{array}{l}-3.042 \\
(8.763)\end{array}$ & $\begin{array}{l}-7.573 \\
(10.30)\end{array}$ & $\begin{array}{c}-16.18^{* * *} \\
(5.369)\end{array}$ & \\
\hline Number $(0=$ No, $1=$ Yes $)$ & $\begin{array}{c}5.083 \\
(11.48)\end{array}$ & $\begin{array}{l}-4.517 \\
(11.00)\end{array}$ & & \\
\hline Female $(0=$ No, $1=$ Yes $)$ & $\begin{array}{c}6.430 \\
(5.997)\end{array}$ & $\begin{array}{l}-1.961 \\
(6.530)\end{array}$ & $\begin{array}{l}-2.013 \\
(3.363)\end{array}$ & $\begin{array}{l}-24.37 \\
(19.24)\end{array}$ \\
\hline Female $\times$ High & $\begin{array}{c}26.19^{* *} \\
(11.47)\end{array}$ & $\begin{array}{c}35.29 * * * \\
(11.29)\end{array}$ & $\begin{array}{c}9.867 \\
(6.124)\end{array}$ & \\
\hline Female $\times$ Low & $\begin{array}{l}-0.180 \\
(11.87)\end{array}$ & $\begin{array}{l}-0.980 \\
(13.62)\end{array}$ & $\begin{array}{c}4.730 \\
(6.913)\end{array}$ & \\
\hline Female $\times$ Number & $\begin{array}{l}-3.805 \\
(14.64)\end{array}$ & $\begin{array}{c}16.53 \\
(14.66)\end{array}$ & & \\
\hline Beliefs & & & & $\begin{array}{c}0.212 \\
(0.359)\end{array}$ \\
\hline Beliefs $\times$ Female & & & & $\begin{array}{l}0.923 * \\
(0.494)\end{array}$ \\
\hline Constant & $\begin{array}{c}26.79 * * * \\
(4.705)\end{array}$ & $\begin{array}{c}-51.40^{* * *} \\
(15.45)\end{array}$ & $\begin{array}{c}38.68^{* * *} \\
(2.579)\end{array}$ & $\begin{array}{c}18.81 \\
(14.01)\end{array}$ \\
\hline Demographic Controls & No & Yes & & \\
\hline$N$ & 273 & 226 & 237 & 237 \\
\hline$R^{2}$ & 0.065 & 0.211 & 0.173 & 0.187 \\
\hline Prob $>$ F & 0.011 & $<0.01$ & $<0.01$ & $<0.01$ \\
\hline
\end{tabular}

Note: contributions, as well as beliefs are reported in percentage of endowment; demographic controls include age, education in years, monthly net income, number of children and climate change attitude; robust standard errors in parentheses; ${ }^{*} p<0.10,{ }^{* *} p<0.05,{ }^{* * *} p<0.01$.

\subsubsection{There Is No Anchoring Confound}

Before moving to the evidence from Experiment 2, we note in passing that an alternative explanation based on anchoring effects can be ruled out as a driver of the treatment effects we observe in the social information treatments. When comparing behaviour between the NUMBER and the BASE treatment, there are no significant differences in average giving (BASE $31 \%$ vs. NUMBER $33 \%$; Mann-Whitney test, $p=0.87$ ). Similarly, the median corresponds to $20 \%$ of the initial endowment in both treatments, and the propensity to give does not differ either.

In contrast to the social information treatments, there is also no evidence that providing a number that does not convey any social information affects the norm perception of subjects. There is no significant difference in stated beliefs between BASE and NUMBER (BASE 38\% vs. NUMBER 39\%; Mann-Whitney test, $p=0.86$ ). Overall, we take this as evidence that anchoring is not a confound when analysing the mechanisms through which social information affects behaviour.

Result 3. Compared to BASE, neither beliefs, nor behaviour differ when subjects are presented with a piece of irrelevant information in NUMBER. 


\subsubsection{Social Information Effects at the Individual Level (Experiment 2)}

The identification of treatment effects in Experiment 1 is based on the assumption that the social information we provide to subjects differs sufficiently from what the median subjects perceives to be the social norm. While this assumption derives its plausibility from the way our treatments are constructed, there might still be considerable individual heterogeneity in norm perception. This raises the natural question whether subjects for whom norm perception deviates more strongly from the social information they receive are more or less reactive to this information. We investigate this question by two major changes in the experimental design vis-à-vis Experiment 1. First, we reverse the task order in Experiment 2. Subjects first state their beliefs and select an initial donation level before receiving information on the average donations made by two other subjects in their session. This allows us to identify to what degree social information and (initially) perceived norms differ for each subject. Subjects are then given a choice between revising their initial decision or confirming it. Thirty seven percent of subjects make use of the opportunity to revise their decision. This significant rate of choice revisions could reflect the fact that more than 90 percent of subjects receive a piece of social information that is not fully in line with their initial behaviour (93\%) or their own expectations (91\%). Deviations to the negative and positive are equally common and almost symmetrically distributed around zero. Most negative deviations fall into the range of $[-2 ; 0]$ and most positive into the range [0;2], but some subjects receive social information that is substantially less in line with their own expectations or behaviour. ${ }^{18}$

In a first step, analogous to Experiment 1, we ask how subjects react to the observed behaviour of others. We do so in a simple regression framework (see Table 3) in which we regress the amount that subjects donate in their final (second) decision on the social information they receive (1). To control for the possibility that this effect depends on how the initial donation amount deviates from the mean donation, we include this amount in Specification 2. In Specifications 3 and 4, we split the sample into those subjects with a below (3) or above (4) median donation amount in the initial stage.

Table 3. Final Choice (Experiment 2).

\begin{tabular}{ccccc}
\hline Dependent Variable & $\begin{array}{c}\mathbf{( 1 )} \\
\text { Donation Final }\end{array}$ & $\begin{array}{c}\mathbf{( 2 )} \\
\text { Donation Final }\end{array}$ & $\begin{array}{c}\mathbf{( 3 )} \\
\text { Donation Final }\end{array}$ & $\begin{array}{c}\mathbf{( 4 )} \\
\text { Donation Final }\end{array}$ \\
\hline Observed Donation of Others & 0.192 & 0.172 & $0.225^{*}$ & 0.432 \\
& $(0.151)$ & $(0.106)$ & $(0.110)$ & $(0.368)$ \\
Initial Donation (Demeaned) & & & & 0.242 \\
& & $0.481^{* * * *}$ & $0.743^{* *}$ & $(0.225)$ \\
Constant & $(0.0897)$ & $(0.318)$ & $1.572^{* * * *}$ \\
& $1.116^{* * * *}$ & $1.150^{* * * *}$ & $1.317^{* * *}$ & $(0.316)$ \\
\hline$N$ & $(0.296)$ & $(0.226)$ & $(0.425)$ & 17 \\
$R^{2}$ & 45 & 45 & 28 & 0.51 \\
Prob $>\mathrm{F}$ & 0.04 & 0.59 & 0.23 & $<0.01$ \\
\hline
\end{tabular}

Robust standard errors in parentheses; ${ }^{*} p<0.10,{ }^{* *} p<0.05,{ }^{* * *} p<0.01,{ }^{* * * *} p<0.001$.

Specification 1 indicates a positive, however statistically insignificant, relationship between the final amount donated and the social information that subjects receive. As approximately half of the subjects receive social information that suggests a lower norm of generosity and approximately half of the subjects receive social information that suggests a higher norm of generosity, this observation is not inconsistent with the findings of Experiment 1. Instead, the null result could simply reflect two opposing effects that cancel each other out. In Specification 2, we account for the possibility that effects of social information might depend on the initial level of generosity, as previously proposed

18 We provide histograms of the full distribution in Figures A1 and A2 of the Appendix. 
in Cason and Mui [27]. While initial and final choices are strongly correlated, we continue to find a positive and statistically insignificant effect of social information. Specifications 3 and 4 complement this analysis by separating the sample into those subjects whose initial donation is below or above the median. The first group is more likely to receive a signal that suggests a higher norm of generosity, while the second group is more likely to receive a signal that suggests a lower norm of generosity. In Specification 3, we observe a weakly significant effect of social information, suggestive of a positive relationship between social information and donations for those subjects who donate little initially. Social information has little effect on subjects who initially donate an above median amount (4). In sum, the effects of receiving social information suggestive of a high donation norm go in the same direction, but are weaker than in Experiment 1.

In the main analysis of Experiment 2, we investigate whether social information leads to a change in behaviour at the individual level and if such a change is more likely to occur when the information received differs more strongly from initial behaviour or empirical expectations. Thirty seven percent of subjects chose to revise their initial decision. According to the proposed mechanism, social information should have a stronger effect on this choice if it conveys new information, i.e., if the absolute difference between the subject's initial donation (or empirical expectations) and the received information is large. Among those subjects who receive information above the median strength, 12 out of 21 revise their initial decision. Conversely, only five out of 24 subjects who receive information below or at the median strength do so. This statistically significant difference (Chi2- test, $p=0.012$ ) could suggest a strong effect along the lines proposed. It could, however, also be a statistical artefact if there is a significant regression towards the mean, i.e., if subjects with more extreme donations in their first decision choose less extreme donations in their revised decision. ${ }^{19}$ To test for this possibility in a regression framework, we follow the ex-post methods described in Barnett et al. [49] and Yu and Chen [50]. Specifically, we estimate four specifications of a probit model with the propensity to revise the amount donated between the initial and final decision as the dependent variable. Results are displayed in Table 4. In Specifications 1 and 2, we investigate whether subjects are more likely to change behaviour if they receive social information that differs more strongly in absolute terms from their initial choice. To control for a potential regression to the mean effect, Specification 2 contains the deviation of the initial choice from the mean donation as an additional control variable. It thus controls for subjects' deviation from the mean donation in their initial decision. Specifications 3 and 4 follow a similar strategy to investigate whether subjects are more likely to change their behaviour upon observing donations of others that differ strongly from their own empirical expectations.

Specifications 1 and 2 indeed suggest that subjects are more likely to revise their initial decision if they observe behaviour of others that differs strongly from their own behaviour. While this effect is strongly significant in Specification 1, it is only weakly significant in Specification 2, which controls for subjects' initial donation amount. This suggests that regression towards the mean may partly account for the observed pattern in Specification 1. Conversely, Specifications 3 and 4 do not suggest that subjects are more likely to change their behaviour upon receiving social information that differs more strongly from their own initial expectations. Jointly, this analysis provides evidence in line with the idea that social information affects pro-social behaviour at the individual level, but also points to important heterogeneities. The observation that social information has a more significant effect on revisions if it deviates from previous behaviour than if it deviates from empirical expectations is interesting and deserves attention in future investigations.

19 We are grateful to an anonymous referee for alerting us to this possibility in an earlier draft. For instance, subjects with a high initial donation are more likely to observe another subject donating less. Any change induced through the observed information will thus go in the same direction as a change resulting from a regression towards the mean. For this reason, we do not analyse the strength of change, where such concerns would be exacerbated [27]. 
Table 4. Choice Revisions (Experiment 2).

\begin{tabular}{|c|c|c|c|c|}
\hline & $\begin{array}{c}\text { (1) } \\
\text { Change } \\
1 \text { = Yes }\end{array}$ & $\begin{array}{c}(2) \\
\text { Change } \\
1=\text { Yes }\end{array}$ & $\begin{array}{c}(3) \\
\text { Change } \\
1=\text { Yes }\end{array}$ & $\begin{array}{c}\text { (4) } \\
\text { Change } \\
1=\text { Yes }\end{array}$ \\
\hline Absolute (Observed-Initial) & $\begin{array}{c}0.319^{* * *} \\
(0.122)\end{array}$ & $\begin{array}{l}0.197 * \\
(0.109)\end{array}$ & & \\
\hline Initial Donation (Demeaned) & & $\begin{array}{l}0.228 * * \\
(0.0974)\end{array}$ & & \\
\hline Absolute (Observed-Belief) & & & $\begin{array}{c}0.142 \\
(0.118)\end{array}$ & $\begin{array}{l}0.0910 \\
(0.121)\end{array}$ \\
\hline Initial Belief (Demeaned) & & & & $\begin{array}{c}0.306^{* *} \\
(0.150)\end{array}$ \\
\hline Constant & $\begin{array}{c}-1.029 * * * \\
(0.331)\end{array}$ & $\begin{array}{c}-0.735^{* *} \\
(0.322)\end{array}$ & $\begin{array}{c}-0.544 * \\
(0.282)\end{array}$ & $\begin{array}{c}-0.480 \text { * } \\
(0.290)\end{array}$ \\
\hline Observations & 45 & 45 & 45 & 45 \\
\hline
\end{tabular}

\section{Discussion and Conclusions}

In light of mounting interest in the importance of norm compliance for economic behaviour [51], we conduct an experimental investigation that adds to the existing evidence base on the role of descriptive social norms for pro-social behaviour. In line with previous experimental investigations [8-10], we find that providing social information that is suggestive of a high contribution norm increases subjects' donations to an existing public good, i.e., a crowding-in effect. This is also in line with peer effects observed for donations in naturally occurring situations [52]. Our study goes one step further by investigating the underlying mechanism for this treatment effect and by adding further robustness to previous findings on the role of empirical expectations for this mechanism $[3,19]$. We find conclusive evidence that social information affects pro-social behaviour through changing the perception of a descriptive norm. Jointly, these observations provide further support for the existence of a mechanism that operates via a preference for conformity. The fact that we rule out anchoring as a potential alternative mechanism that could have confounded the interpretation of earlier investigations and the fact that we derive our results from a non-standard sample drawn from the general population add further robustness to the generality of our results.

Our experiments also highlight that there might be important and overlooked heterogeneities in individuals' reactions towards social information. First, our exploratory analyses point to subtle gender differences in how individuals react to social information. While members of both genders update their empirical expectations upon observing social information, only females react to an updated norm in a way that would be in line with preferences for conformity. In our experiment this gender difference is sufficiently strong to fully account for the observation that only females increase their donations upon receiving social information that suggest generosity to be the norm. Given the purely exploratory nature of this finding, it would be worth studying more formally and explicitly to what degree this observation generalizes beyond the context and subject pool we study here. Second, results from Experiment 2 show that individuals are most likely to react to social information if this information conveys a norm that strongly deviates from their own behaviour, yet they show little reaction if it strongly deviates from their own expectations.

A better understanding of the underlying mechanisms and of these heterogeneities is not purely of theoretical interest. In the context of climate change mitigation-the public good that subjects can contribute to in our experiment-it has been recently argued that norm change can be an important behavioural driver for increasing mitigation efforts [53]. Our findings show that 
influencing the flow of social information can indeed be an effective tool for policy makers to influence individuals' mitigation choices, contributing to a broader literature on the role of social norms for pro-environmental behaviour [54]. However, we show that using social information in this way might not be uniformly effective across all individuals as suggested by a heterogeneous treatment effect by gender. Policy makers should also be aware that negative social information might more than offset positive social information such that vicious circles between observed behaviour and norm perception can emerge over time. For instance, studies on energy conservation and social information nudges frequently observe so-called boomerang effects among individuals who learn that they conserve more energy than their peers and subsequently increase their energy consumption [55]. Especially in situations where a majority of individuals engage in a behaviour that is socially disapproved of and this behaviour is otherwise not easily observable, it has been argued that policy makers could instead communicate an injunctive norm to prevent creating a shared expectation of 'everybody does this' [56]. However, as shown in Bicchieri and Xiao [3], when descriptive and injunctive norms are both observable and send conflicting messages, it is mostly the former that significantly impact behaviour. The mechanism, we study here also highlights that social norm interventions might be unsuccessful for two separate reasons: either the presented information does not change the perception of the norm or a change in norm perception does not reflect on actual behaviour.

Compared to naturally occurring situations, we simplify the decision environment in our experiment along multiple dimensions, and thus, we believe that relaxing some of these simplifications can shed further light on the process of norm formation. Introducing additional contextual factors could shed further light on the transmission mechanisms between social information, norm perception and behaviour. For our experimental participants, it is easy and costless to observe others' behaviour. They are provided with concise information immediately before making their own decision. In reality, it might be significantly more difficult or even costly to observe others. In most instances, it is also necessary to interpret others' noisy behaviour, which clouds inference on the underlying social norm. Another contextual factor that could affect the role of social information is its source. In Experiment 1 , we provide participants with information on fifty unspecific participants from previous sessions. It appears plausible that individuals care more about conforming with norms that prevail within an subjectively relevant group. For instance, findings from Goldstein et al. [30] and Costa and Kahn [57] suggest that preferences for conformity could be much stronger, if the decision maker receives information from a demographically or ideologically similar group of individuals.

Author Contributions: All authors contributed in equal parts to the conception and design of the experiments. Data were collected and analysed by S.E.K. and J.L. The initial draft was composed by S.E.K., J.L. and T.G. Later revisions to this draft were made by T.G., J.L. and C.S.

Funding: This research was funded by German Ministry for Education and Research under grant number 01UV1012. The APC was funded by the Knowledge Unlatched initiative.

Conflicts of Interest: The authors declare no conflict of interest.

\section{Appendix A. Procedure}

Appendix A.1. General Instructions

General Instructions were handed to participants as a print-out. 


\begin{tabular}{ll}
\hline Check-in & Check-in room: \\
& Sign-in and generation of personal code \\
\hline Experiment & Laboratory: \\
& Random seat assignment \\
& General instructions read out loud (page 17) \\
& Tasks implemented in z-Tree \\
& • Contribution to climate change mitigation (page 18) \\
& - Belief elicitation (page 20) \\
& Payment receipt distributed according to personal code \\
\hline Payment & Check-in room: \\
& Subjects exchange payment receipt for cash \\
\hline
\end{tabular}

\section{General Information}

Dear participant, Thank you for participating in this study. In the following you will be informed about the rules and procedures. You have the opportunity to earn money. The payment depends on your decisions during the experiment. Every participant has received the same printed instructions as you did. Please take your time and read the instructions carefully.

\section{No communication with other participants}

Please do not communicate with the other participants. Otherwise we are forced to exclude you from the experiment and you will have to forgo your payment. If you have any questions, please raise your hand. The experimenter will answer your question quietly.

\section{Procedure}

Please make sure that you created your personal code. During today's experiment, you will be asked to insert your personal code. Your personal code ensures your decisions during the study to be anonymous. The experiment is taking place at the computer and your tasks are explained step-by-step. Please read the instructions on the screen thoroughly. If amounts of money are mentioned for a task, these amounts refer to real payments being paid out-depending on your decisions-at the end of the experiment.

It is important that you answer all questions; your data is treated anonymously.

Thank you!

\section{Appendix A.1.1. Real Contribution Task}

\section{General Instructions}

Dear participant,

Thank you for supporting our research. On this screen you receive general instructions on the procedure. You will take several tasks. Please follow the instructions on the screen.

At the end of today's experiment you receive your payment. At several points you can influence your payment by your own decisions. Whenever this is the case you will be informed on the screen and you will receive information on how to make your decisions.

Your decisions are anonymous. This is guaranteed by your personal code. In addition, you receive your payment at the end in room 00.005 a (check-in room). Therefore, the experimenters will not receive information on your decisions and payments.

\section{$---$}

For your participation you receive ten Euro.

These ten Euro are paid to you at the end of today's experiment in cash. Alternatively, we offer you to use a share of these ten Euro to reduce global $\mathrm{CO}_{2}$ emissions. In the following we explain how it is possible for us to reduce global $\mathrm{CO}_{2}$ emissions. 


\section{What is $\mathrm{CO}_{2}$ ?}

$\mathrm{CO}_{2}$ is a gas which is emitted by burning oil, coal, or fuel. It accrues from the manufacturing of goods or the production of electricity as well as from travel by car or airplane.

\section{Why does one try to reduce $\mathrm{CO}_{2}$ ?}

The more $\mathrm{CO}_{2}$ gets into earth's atmosphere, the more likely becomes the occurrence of the environmental problem climate change. Scientists expect climate change to cause consequences such as the rise of sea levels, the stronger spread of tropical diseases, or smaller yields in agriculture.

How is it possible to reduce $\mathrm{CO}_{2}$ emissions?

Within the European Union a binding limit has been installed which constitutes how much $\mathrm{CO}_{2}$ may be emitted by large industrial companies. In order to emit $\mathrm{CO}_{2}$, these companies need emission permits. These permits can be purchased from the emission-trading-registry of the Federal Environmental Agency. After purchase these permits are not available to companies any longer. In this way, European $\mathrm{CO}_{2}$ emissions are reduced by the amount of purchased permits. As the climatic system reacts inertly to a change in $\mathrm{CO}_{2}$ emissions, the reduction action contributes only in approximately 50 years towards noticeable climate change mitigation.

\section{What do we offer to you?}

As soon as you completed reading the informational text, we offer you to purchase permits from the German emission-trading-registry of the Federal Environmental Agency from your ten Euro. For each Euro you can mitigate emissions of approximately $70 \mathrm{~kg} \mathrm{CO}_{2}$, i.e., with your ten Euro you can reduce $\mathrm{CO}_{2}$ emissions by a total of $700 \mathrm{~kg}$. For example, $70 \mathrm{~kg}$ correspond to $\mathrm{CO}_{2}$ emissions arising from a drive from Frankfurt am Main to Hamburg by car.

On average a German citizen emits 9 tons of $\mathrm{CO}_{2}$ per year (one ton equals $1000 \mathrm{~kg}$ ). Therefore, $700 \mathrm{~kg}$, which may be reduced with your 10 Euro, correspond to a little less than the monthly $\mathrm{CO}_{2}$ emissions of an average German.

\section{How can you verify that your contribution was used to retire $\mathrm{CO}_{2}$ permits?}

As permits for $\mathrm{CO}_{2}$ emissions are purchased through the emission-trading-registry of the Federal Environmental Agency, the procedure can be monitored transparently. At the end of this study a certificate of reduction -issued by the emission-trading-registry- will be posted at the notice board of the Chair of Behavioural Economics (Prof. Dr. C. Schwieren).

\section{Purchasing $\mathrm{CO}_{2}$ permits}

On the following screen you may indicate the share of your ten Euro you would like to spend on $\mathrm{CO}_{2}$ permits.

Social Information Treatments: In previous sessions of the experiment 50 participants gave $€ 7 / € 1$ on average to retire $\mathrm{CO}_{2}$ permits.

Number Treatment: In previous sessions of the experiment 50 participants lived within a $7 \mathrm{~km}$ radius around Heidelberg. 
On this screen you may purchase emission permits from a share of your ten Euros.

- Please insert into the blue field how much money you would like to use to retire $\mathrm{CO}_{2}$ permits and thus reduce global $\mathrm{CO}_{2}$ emissions.

- You are free to indicate every integer between 0 and 10 Euro, i.e., you may fill in whole numbers without decimal place (period or comma).

- Each Euro you are not using to purchase $\mathrm{CO}_{2}$ permits, you can take home at the end in cash.

$<$ insert decision $>$

$<$ summary screen displayed $>$

$---$

\section{Appendix A.1.2. Instructions Estimates}

In the following we ask you to appreciate the behaviour of the other participants in the room.

You should estimate how the other participants in the room decided on purchasing $\mathrm{CO}_{2}$ permits.

Depending on the accuracy of the estimate, you receive additional money.

$---$

\section{Payment:}

For your estimate you may receive additional payments. The more accurate your estimate of the other participants, the more money you receive.

\section{Calculation:}

If your estimate deviates by 0.5 Euro (above or below) from the true value of today's session, you receive 2 Euro.

If your estimate deviates by 1.5 Euro (above or below) from the true value of today's session, you receive 1 Euro.

\section{Question:}

What do you think: How much did other participants on average give to purchase $\mathrm{CO}_{2}$ permits?

$<$ insert estimate $>$

Appendix A.1.3. Instructions Experiment 2: Procedures

The contribution and belief elicitation task are equivalent to Experiment 1 . We will thus only describe the remaining screens (Social information, Revision).

Appendix A.1.4. Instructions Experiment 2: Social Information

We will show you now the average amount that two randomly selected participants in this room have contributed. You will not receive any additional information regarding the identity of these participants.

The other two participants have contributed $<A V E R A G E>$ Euro on average

Appendix A.1.5. Instructions Experiment 2: Revision

On this screen we are giving you the opportunity to change your initial contributions. At the end of the experiment the decision you make on this screen will determine the outcome. 
If you don't want to change your initial contribution please enter the same amount as before into the blue field

If you want to change your initial contribution please enter the new amount into the blue field

$---$

$<$ insert decision $>$

Appendix A.1.6. Additional Tables and Results

Table A1 summarizes the demographic composition across the four treatments of Experiment 1.

Table A1. Sample properties.

\begin{tabular}{lccccc}
\hline & $\begin{array}{c}\text { Baseline } \\
\text { N= 144 }\end{array}$ & $\begin{array}{c}\text { High } \\
\mathbf{N = 4 7}\end{array}$ & $\begin{array}{c}\text { Low } \\
\mathbf{N = 4 7}\end{array}$ & $\begin{array}{c}\text { Number } \\
\mathbf{N = 3 6}\end{array}$ & $\begin{array}{c}\text { Pooled } \\
\mathbf{N = \mathbf { 2 7 4 }}\end{array}$ \\
\hline Age (Years) & 48.79 & 44.60 & 46.53 & 50.03 & 47.85 \\
Female (\%) & $62.94 \%$ & $46.81 \%$ & $48.94 \%$ & $55.56 \%$ & $56.78 \%$ \\
Education (Years) & 14.15 & 13.81 & 14.39 & 14.11 & 14.12 \\
Monthly Net Income (€) & 1232.80 & 1404.65 & 1748.39 & 1818.97 & 1409.87 \\
Assets (\%) & $38.89 \%$ & $29.79 \%$ & $40.43 \%$ & $44.44 \%$ & $38.32 \%$ \\
Household Size & 2.11 & 1.79 & 1.89 & 2.06 & 2.02 \\
Number of Children & 0.92 & 0.85 & 0.79 & 0.88 & 0.88 \\
Climate Change Attitude & 5.72 & 5.77 & 5.86 & 5.49 & 5.72 \\
\hline
\end{tabular}

Note: the table reports mean values; climate change attitude corresponds to a mean score of four questionnaire items retrieved from a 7-point Likert-scale; it includes belief in the existence of climate change, perceived consequences of climate change arising and concern for one's self and future generations; the scales range from 1 (not convinced/concerned) to 7 (very convinced/concerned).

In Table A2, we display the results of several OLS-regressions controlling for different sets of demographic attributes. ${ }^{20}$ The coefficients for the three treatment dummies (HIGH, LOW, IRRELEVANT) provide further support for the key results obtained from non-parametric tests: the coefficient for HIGH is positive and significant in all three specifications, whereas the coefficient for LOW is insignificant throughout. Providing irrelevant information also has no significant impact on giving. Some of the coefficients for the control variables are in line with previous findings from the literature on pro-social behaviour and indicate a positive relationship with age $[43,58]$ and gender. Unsurprisingly, those subjects stating a greater concern for the public good provided by their donations (climate change mitigation) give higher amounts.

Table A2. Regression results: treatment effects and demographic attributes.

\begin{tabular}{cccc}
\hline & $\mathbf{( 1 )}$ & $\mathbf{( 2 )}$ & $\mathbf{( 3 )}$ \\
\hline Dependent Variable & Contributions & Contributions & Contributions \\
\hline High $(0=$ No, $1=$ Yes $)$ & $17.47^{* * *}$ & $17.34^{* * *}$ & $18.27^{* * *}$ \\
& $(5.521)$ & $(6.079)$ & $(5.489)$ \\
Low $(0=$ No, $1=$ Yes $)$ & -1.367 & -7.014 & -2.479 \\
& $(5.901)$ & $(6.875)$ & $(6.439)$ \\
Number $(0=$ No, $1=$ Yes $)$ & 2.726 & 4.514 & 4.152 \\
& $(6.924)$ & $(7.375)$ & $(6.720)$ \\
\hline
\end{tabular}

20 Tobit regressions that control for potential censoring of the outcome variable arrive at the same conclusions and are available from the authors upon request. 
Table A2. Cont.

\begin{tabular}{|c|c|c|c|}
\hline & (1) & (2) & (3) \\
\hline Dependent Variable & Contributions & Contributions & Contributions \\
\hline Age (Years) & $\begin{array}{c}0.481^{* * *} \\
(0.118)\end{array}$ & $\begin{array}{c}0.633^{* * *} \\
(0.170)\end{array}$ & $\begin{array}{c}0.519 * * * \\
(0.156)\end{array}$ \\
\hline Female $(0=$ No, $1=$ Yes $)$ & $\begin{array}{c}11.34^{* * *} \\
(4.241)\end{array}$ & $\begin{array}{c}7.438 \\
(4.846)\end{array}$ & $\begin{array}{l}7.553 * \\
(4.538)\end{array}$ \\
\hline Education (Years) & & $\begin{array}{c}0.570 \\
(0.723)\end{array}$ & $\begin{array}{c}0.632 \\
(0.677)\end{array}$ \\
\hline Monthly Net Income $(€)$ & & $\begin{array}{l}-0.00157 \\
(0.00265)\end{array}$ & \\
\hline Household Size & & $\begin{array}{c}4.179 * * \\
(1.984)\end{array}$ & $\begin{array}{l}4.446^{* *} \\
(1.929)\end{array}$ \\
\hline Number of Children & & $\begin{array}{l}-0.886 \\
(2.547)\end{array}$ & $\begin{array}{l}-0.776 \\
(2.395)\end{array}$ \\
\hline Climate Change Attitude (1-7) & & $\begin{array}{c}6.116^{* * *} \\
(1.699)\end{array}$ & $\begin{array}{c}6.501 * * * \\
(1.604)\end{array}$ \\
\hline Assets $(0=$ No, $1=$ Yes $)$ & & & $\begin{array}{c}2.200 \\
(5.006)\end{array}$ \\
\hline Constant & $\begin{array}{c}0.242 \\
(6.645)\end{array}$ & $\begin{array}{c}-52.73^{* * *} \\
(15.54)\end{array}$ & $\begin{array}{c}-54.70 * * * \\
(14.64)\end{array}$ \\
\hline$N$ & 273 & 226 & 257 \\
\hline$R^{2}$ & 0.098 & 0.174 & 0.171 \\
\hline Prob $>$ F & $<0.01$ & $<0.01$ & $<0.01$ \\
\hline
\end{tabular}

Note: contributions are reported in percentage of endowment; robust standard errors in parentheses; ${ }^{*} p<0.10,{ }^{* *} p<0.05,{ }^{* * *} p<0.01$.

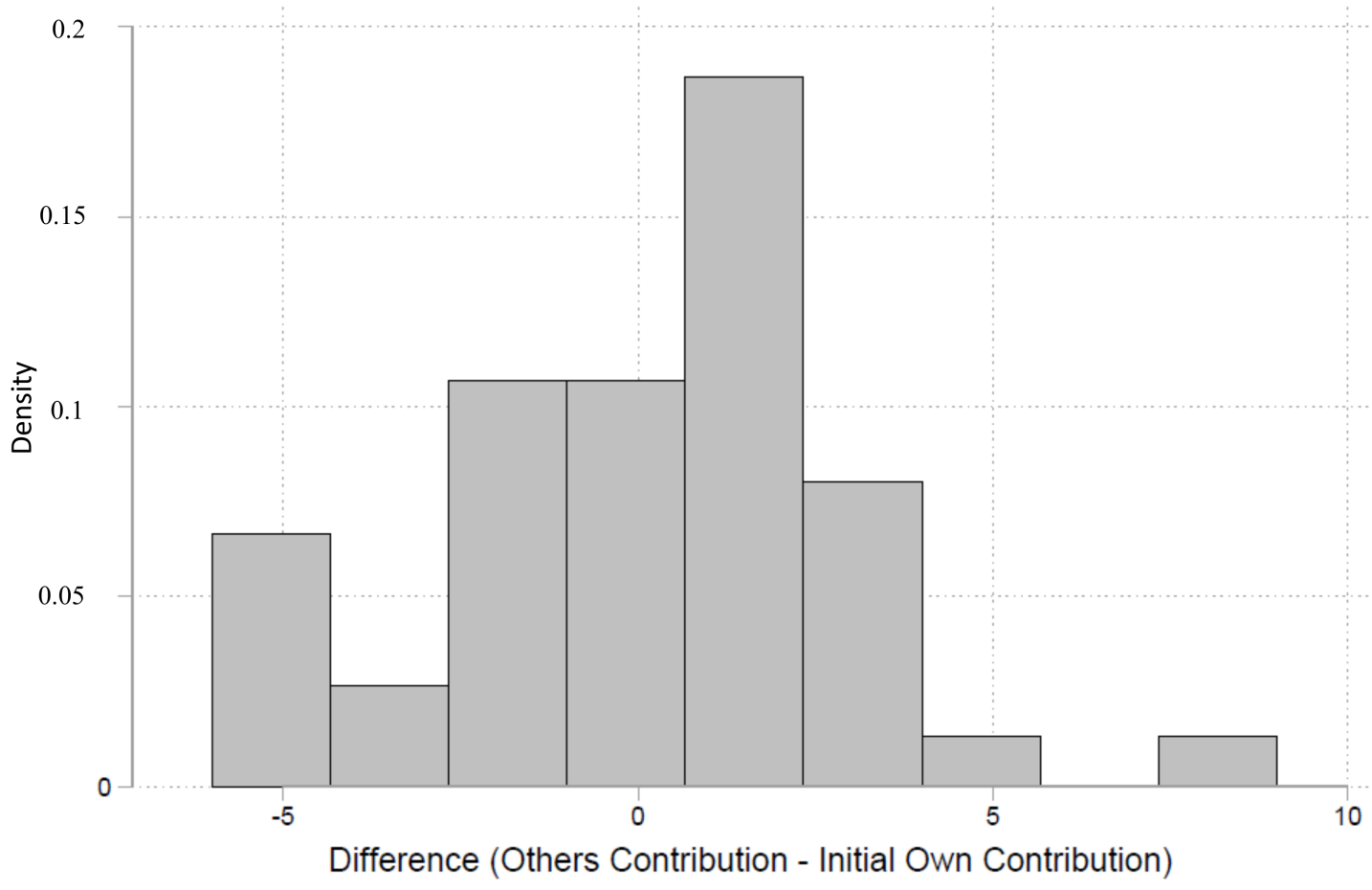

Figure A1. Histogram diverging behaviour. 


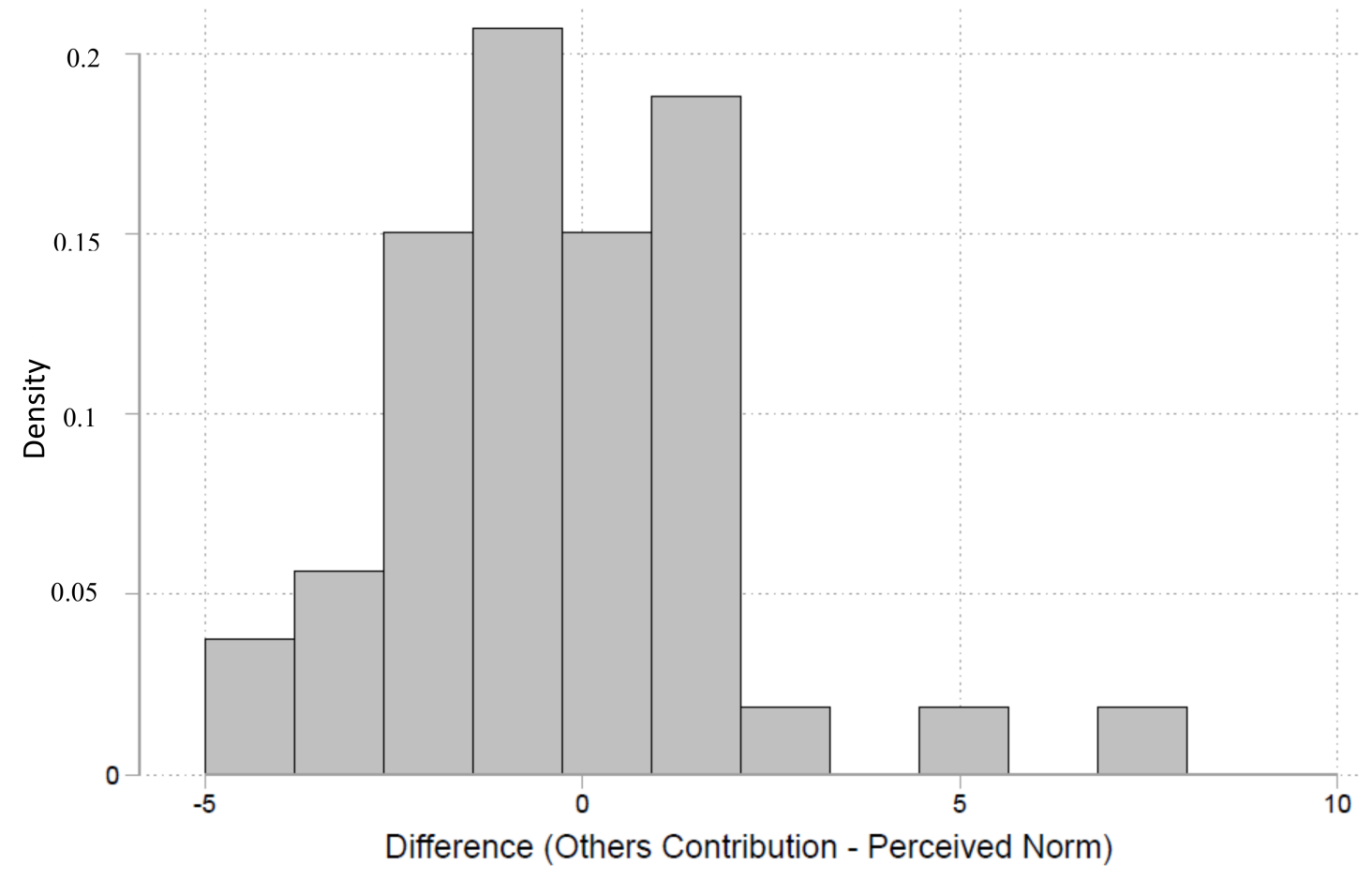

Figure A2. Histogram diverging beliefs.

\section{References}

1. Cialdini, R.B.; Reno, R.R.; Kallgren, C.A. A focus theory of normative conduct: Recycling the concept of norms to reduce littering in public places. J. Personal. Soc. Psychol. 1990, 58, 1015. [CrossRef]

2. López Pérez, R. Aversion to norm-breaking: A model. Games Econ. Behav. 2008. [CrossRef]

3. Bicchieri, C.; Xiao, E. Do the right thing: But only if others do so. J. Behav. Decis. Mak. 2009, 22, $191-208$. [CrossRef]

4. Krupka, E.; Weber, R.A. The focusing and informational effects of norms on pro-social behaviour. J. Econ. Psychol. 2009, 30, 307-320. [CrossRef]

5. Krupka, E.L.; Weber, R.A. Identifying social norms using coordination games: Why does dictator game sharing vary? J. Eur. Econ. Assoc. 2013, 11, 495-524. [CrossRef]

6. Gächter, S.; Nosenzo, D.; Sefton, M. Peer effects in pro-social behaviour: Social norms or social preferences? J. Eur. Econ. Assoc. 2013, 11, 548-573. [CrossRef] [PubMed]

7. Bicchieri, C. The Grammar of Society: The Nature and Dynamics of Social Norms; Cambridge University Press: Cambridge, UK, 2005.

8. Shang, J.; Croson, R. A field experiment in charitable contribution: The impact of social information on the voluntary provision of public goods. Econ. J. 2009, 119, 1422-1439. [CrossRef]

9. Frey, B.S.; Meier, S. Social Comparisons and Pro-social Behavior: Testing "Conditional Cooperation" in a Field Experiment. Am. Econ. Rev. 2004, 94, 171-1722. [CrossRef]

10. Alpizar, F.; Carlsson, F.; Johansson-Stenman, O. Anonymity, reciprocity, and conformity: Evidence from voluntary contributions to a national park in Costa Rica. J. Public Econ. 2008, 92, 1047-1060. [CrossRef]

11. Allcott, H. Social norms and energy conservation. J. Public Econ. 2011, 95, 1082-1095. [CrossRef]

12. Margetts, H.; John, P.; Escher, T.; Reissfelder, S. Social information and political participation on the internet: An experiment. Eur. Political Sci. Rev. 2011, 3, 321-344. [CrossRef]

13. Robert, I.; Arnab, M. Is dishonesty contagious? Econ. Inq. 2013, 51, 722-734. [CrossRef]

14. Beshears, J.; Choi, J.J.; Laibson, D.; Madrian, B.C.; Milkman, K.L. The effect of providing peer information on retirement savings decisions. J. Financ. 2015, 70, 1161-1201. [CrossRef] [PubMed]

15. Coffman, L.C.; Featherstone, C.R.; Kessler, J.B. Can social information affect what job you choose and keep? Am. Econ. J. Appl. Econ. 2017, 9, 96-117. [CrossRef]

16. Bernheim, B.D. A theory of conformity. J. Political Econ. 1994, 102, 841-877. [CrossRef] 
17. Bénabou, R.; Tirole, J. Incentives and prosocial behaviour. Am. Econ. Rev. 2006, 96, 1652-1678. [CrossRef]

18. Grossman, Z. Self-signaling and social-signaling in giving. J. Econ. Behav. Organ. 2015, 117, 26-39. [CrossRef]

19. Croson, R.; Handy, F.; Shang, J. Keeping up with the Joneses: The relationship of perceived descriptive social norms, social information, and charitable giving. Nonprofit Manag. Leadersh. 2009, 19, 467-489. [CrossRef]

20. Eckel, C.C.; Grossman, P.J. Rebate versus matching: does how we subsidize charitable contributions matter? J. Public Econ. 2003, 87, 681-701. [CrossRef]

21. Keser, C.; Van Winden, F. Conditional cooperation and voluntary contributions to public goods. Scand. J. Econ. 2000, 102, 23-39. [CrossRef]

22. Fischbacher, U.; Gächter, S.; Fehr, E. Are people conditionally cooperative? Evidence from a public goods experiment. Econ. Lett. 2001, 71,397-404. [CrossRef]

23. Chaudhuri, A. Sustaining cooperation in laboratory public goods experiments: a selective survey of the literature. Exp. Econ. 2011, 14, 47-83. [CrossRef]

24. Harrison, G.W.; List, J.A. Field experiments. J. Econ. Lit. 2004, 42, 1009-1055. [CrossRef]

25. Smith, A. Estimating the causal effect of beliefs on contributions in repeated public good games. Exp. Econ. 2013, 16, 414-425. [CrossRef]

26. Costa-Gomes, M.A.; Huck, S.; Weizsäcker, G. Beliefs and actions in the trust game: Creating instrumental variables to estimate the causal effect. Games Econ. Behav. 2014, 88, 298-309. [CrossRef]

27. Cason, T.N.; Mui, V.L. Social influence in the sequential dictator game. J. Math. Psychol. 1998, 42, $248-265$. [CrossRef] [PubMed]

28. Diederich, J.; Goeschl, T. To mitigate or not to mitigate: The price elasticity of pro-environmental behaviour. J. Environ. Econ. Manag. 2017, 84, 209-222. [CrossRef]

29. Löschel, A.; Sturm, B.; Vogt, C. The demand for climate protection-Empirical evidence from Germany. Econ. Lett. 2012, 118, 415-418. [CrossRef]

30. Goldstein, N.J.; Cialdini, R.B.; Griskevicius, V. A room with a viewpoint: Using social norms to motivate environmental conservation in hotels. J. Consum. Res. 2008, 35, 472-482. [CrossRef]

31. Ortmann, A.; Hertwig, R. The costs of deception: Evidence from psychology. Exp. Econ. 2002, 5, 111-131. [CrossRef]

32. Colson, G.; Corrigan, J.R.; Grebitus, C.; Loureiro, M.L.; Rousu, M.C. Which deceptive practices, if any, should be allowed in experimental economics research? Results from surveys of applied experimental economists and students. Am. J. Agric. Econ. 2015, 98, 610-621. [CrossRef]

33. Elster, J. Social norms and economic theory. J. Econ. Perspect. 1989, 3, 99-117. [CrossRef]

34. Fischbacher, U. z-Tree: Zurich toolbox for ready-made economic experiments. Exp. Econ. 2007, 10, 171-178. [CrossRef]

35. Goeschl, T.; Kettner, S.E.; Lohse, J.; Schwieren, C. What Do We Learn from Public Good Games about Voluntary Climate Action? Evidence from an Artefactual Field Experiment; AWI Working Paper Series; SSRN: Rochester, NY, USA, 2015.

36. Greiner, B. The Online Recruitment System Orsee 2.0-A Guide for The Organization of Experiments in Economics; Working Paper Series; University of Cologne: Köln, Germany, 2004; Volume 10.

37. Roberts, R.D. A positive model of private charity and public transfers. J. Political Econ. 1984, 92, 136-148. [CrossRef]

38. Andreoni, J. Impure altruism and donations to public goods: A theory of warm-glow giving. Econ. J. 1990, 100, 464-477. [CrossRef]

39. Jones, S.R. The Economics of Conformism; Blackwell: Oxford, UK, 1984.

40. Croson, R.; Shang, J.Y. The impact of downward social information on contribution decisions. Exp. Econ. 2008, 11, 221-233. [CrossRef]

41. Ariely, D.; Loewenstein, G.; Prelec, D. "Coherent arbitrariness": Stable demand curves without stable preferences. Q. J. Econ. 2003, 118, 73-106. [CrossRef]

42. Diederich, J.; Goeschl, T. Willingness to pay for voluntary climate action and its determinants: Field-experimental evidence. Environ. Resour. Econ. 2013, 57, 1-25. [CrossRef]

43. Carpenter, J.; Connolly, C.; Myers, C.K. Altruistic behaviour in a representative dictator experiment. Exp. Econ. 2008, 11, 282-298. [CrossRef]

44. Baron, R.M.; Kenny, D.A. The moderator-mediator variable distinction in social psychological research: Conceptual, strategic, and statistical considerations. J. Personal. Soc. Psychol. 1986, 51, 1173-1182. [CrossRef] 
45. Sobel, M.E. Asymptotic confidence intervals for indirect effects in structural equation models. Sociol. Methodol. 1982, 13, 290-312. [CrossRef]

46. de Oliveira, A.C.; Spraggon, J.M.; Denny, M.J. Instrumenting beliefs in threshold public goods. PLoS ONE 2016, 11, e0147043. [CrossRef] [PubMed]

47. Croson, R.; Gneezy, U. Gender differences in preferences. J. Econ. Lit. 2009, 47, 448-474. [CrossRef]

48. Croson, R.; Handy, F.; Shang, J. Gendered giving: The influence of social norms on the donation behaviour of men and women. Int. J. Nonprofit Volunt. Sect. Mark. 2010, 15, 199-213. [CrossRef]

49. Barnett, A.G.; Van Der Pols, J.C.; Dobson, A.J. Regression to the mean: what it is and how to deal with it. Int. J. Epidemiol. 2004, 34, 215-220. [CrossRef] [PubMed]

50. Yu, R.; Chen, L. The need to control for regression to the mean in social psychology studies. Front. Psychol. 2015, 5, 1574. [CrossRef] [PubMed]

51. Kimbrough, E.O.; Vostroknutov, A. Norms make preferences social. J. Eur. Econ. Assoc. 2016, 14, 608-638. [CrossRef]

52. Smith, S.; Windmeijer, F.; Wright, E. Peer effects in charitable giving: Evidence from the (running) field. Econ. J. 2014, 125, 1053-1071. [CrossRef]

53. Nyborg, K.; Anderies, J.M.; Dannenberg, A.; Lindahl, T.; Schill, C.; Schlüter, M.; Adger, W.N.; Arrow, K.J.; Barrett, S.; Carpenter, S.; et al. Social norms as solutions. Science 2016, 354, 42-43. [CrossRef] [PubMed]

54. Farrow, K.; Grolleau, G.; Ibanez, L. Social norms and pro-environmental behaviour: A review of the evidence. Ecol. Econ. 2017, 140, 1-13. [CrossRef]

55. Allcott, H.; Rogers, T. The short-run and long-run effects of behavioural interventions: Experimental evidence from energy conservation. Am. Econ. Rev. 2014, 104, 3003-3037. [CrossRef]

56. Cialdini, R.B.; Demaine, L.J.; Sagarin, B.J.; Barrett, D.W.; Rhoads, K.; Winter, P.L. Managing social norms for persuasive impact. Soc. Influ. 2006, 1, 3-15. [CrossRef]

57. Costa, D.L.; Kahn, M.E. Energy conservation "nudges" and environmentalist ideology: Evidence from a randomized residential electricity field experiment. J. Eur. Econ. Assoc. 2013, 11, 680-702. [CrossRef]

58. List, J.A. Young, Selfish and Male: Field evidence of social preferences. Econ. J. 2004, 114, 121-149. [CrossRef]

(C) 2018 by the authors. Licensee MDPI, Basel, Switzerland. This article is an open access article distributed under the terms and conditions of the Creative Commons Attribution (CC BY) license (http:/ / creativecommons.org/licenses/by/4.0/). 